\title{
EFFECT OF RESERPINE ON THE LESSER CIRCULATION IN CHRONIC PULMONARY DISEASES
}

\author{
BY \\ J. WIDIMSKÝ, J. KASALICKÝ, R. DEJDAR, Z. VYSLOUŽIL, \\ AND M. LUKES̆ \\ From the Institute for Cardiovascular Research, Prague, Czechoslovakia \\ Received August 14, 1961
}

Investigations of the effect of pharmacological preparations on pulmonary hypertension in man are important for several reasons: from the potential therapeutic aspect; because these data may help to elucidate the regulation of pressure in the pulmonary artery; and finally because they may show whether pulmonary hypertension is reversible or irreversible. While the effect of reserpine on hypertension in the greater circulation is well known, there are only general papers on the effect of reserpine on hypertension in the lesser circulation. Angelino and Levi (1956) and Halmagyi et al. (1957) demonstrated that pulmonary hypertension can be influenced by reserpine in patients with mitral stenosis. Halmagyi (1959) suggested later that reserpine could be used therapeutically in patients with pulmonary hypertension in chronic pulmonary disease. This possibility was, however, not tested clinically. We decided therefore to investigate the influence of reserpine on pulmonary hypertension in a group of patients with chronic pulmonary disease.

\section{METHOD}

Cardiac catheterization was performed on a group of 17 patients with pulmonary disease. There were 10 suffering with pulmonary tuberculosis at different stages, mostly fibro-caseous with cavities, 6 with silicosis (all stage 3), and one with successive embolization of the pulmonary artery (Table I). The catheterization was done in the morning without pre-medication. After insertion of the catheter into the pulmonary trunk, a Cournand needle was introduced into the femoral artery under local anæsthesia. The zero level was adjusted to $10 \mathrm{~cm}$. above the table on which the patient was lying. Subsequently a reading of the pressure in the pulmonary artery was taken (using an Elema electromanometer): the pulse rate and brachial artery pressure (by auscultation) were recorded at 5-minute intervals for 30-40 minutes. The mean brachial pressure was determined by adding one-third of the pressure amplitude to the diastolic pressure. At the end of the rest period the oxygen consumption was estimated. The expired air was collected in a Douglas bag for 5 minutes and analysed by a Zeiss interferometer. Blood specimens from the pulmonary artery and the femoral artery were withdrawn 10 and 30 and, in some instances, 40 minutes after the rest period. The oxygen saturation of the blood was determined by a Brinkman hæmoreflectometer.* The hæmoglobin content was determined photometrically. The cardiac output was calculated according to Fick's principle. The pulmonary capillary venous pressure was determined at the onset and at the end of the period. Subsequently 1-2 mg. serpasil (Ciba) diluted in $10 \mathrm{ml}$. saline were injected into the trunk of the pulmonary artery or the right ventricle during two minutes.

* Kipp, Delft. 
TABLE I

Clinical Data of Individual Patients

\begin{tabular}{|c|c|c|c|c|c|c|}
\hline No. & Patient & Age & Sex & Diagnosis & $\begin{array}{c}\text { Serpasil } \\
\text { (dose in mg.) }\end{array}$ & $\begin{array}{c}\text { Mean pressure PA } \\
\text { before and after } \\
\text { serpasil }\end{array}$ \\
\hline $\begin{array}{r}1 \\
2 \\
3 \\
4 \\
5 \\
6 \\
7 \\
8 \\
9 \\
10 \\
11 \\
12 \\
13 \\
14 \\
15 \\
16 \\
17\end{array}$ & $\begin{array}{l}\text { P.M. } \\
\text { B.V. } \\
\text { V.F. } \\
\text { V.J. } \\
\text { J.J. } \\
\text { B.M. } \\
\text { Z.F. } \\
\text { H.M. } \\
\text { V.F. } \\
\text { V.F. } \\
\text { S.R. } \\
\text { K.S. } \\
\text { P.F. } \\
\text { K.J. } \\
\text { R.W. } \\
\text { T... } \\
\text { S.M. }\end{array}$ & $\begin{array}{l}38 \\
55 \\
48 \\
50 \\
20 \\
60 \\
66 \\
35 \\
39 \\
46 \\
36 \\
35 \\
40 \\
60 \\
53 \\
46 \\
42\end{array}$ & $\begin{array}{l}\text { F. } \\
\text { M. } \\
\text { M. } \\
\text { M. } \\
\text { F. } \\
\text { M. } \\
\text { M. } \\
\text { M. } \\
\text { M. } \\
\text { F. } \\
\text { F. } \\
\text { M. } \\
\text { M. } \\
\text { M. } \\
\text { M. } \\
\text { M. } \\
\text { F. }\end{array}$ & $\begin{array}{l}\text { PT } \\
\text { PT } \\
\text { Sil } \\
\text { Sil } \\
\text { PT } \\
\text { PT } \\
\text { PT } \\
\text { Sil } \\
\text { PT } \\
\text { PT } \\
\text { PT } \\
\text { PT } \\
\text { PT } \\
\text { Sil } \\
\text { Sil } \\
\text { Sil } \\
\text { Emb. }\end{array}$ & $\begin{array}{l}1 \\
1 \\
1 \\
1 \\
1 \\
1 \\
1 \\
1 \\
1 \\
2 \\
2 \\
2 \\
2 \\
2 \\
2 \\
2 \\
2\end{array}$ & $\begin{array}{l}68 \cdot 1-64 \cdot 8 \\
39 \cdot 7-30 \cdot 2 \\
20 \cdot 8-16 \cdot 2 \\
28 \cdot 6-23 \cdot 8 \\
25 \cdot 8-19 \cdot 3 \\
16 \cdot 4-13 \cdot 7 \\
24 \cdot 1-20 \cdot 9 \\
17 \cdot 2-17 \cdot 1 \\
25 \cdot 4-22 \cdot 0 \\
20 \cdot 2-16 \cdot 3 \\
32 \cdot 4-23 \cdot 6 \\
21 \cdot 4-20 \cdot 0 \\
18 \cdot 0-19 \cdot 1 \\
20 \cdot 7-16 \cdot 6 \\
22 \cdot 5-18 \cdot 2 \\
21 \cdot 1-17 \cdot 9 \\
41 \cdot 1-36 \cdot 0\end{array}$ \\
\hline
\end{tabular}

The pressure in the pulmonary artery, the brachial artery pressure, and pulse rate were assessed immediately after injection and subsequently at 10,30 , and 60 minute intervals after injection.

The oxygen consumption was determined in all patients between 30 and 35 minutes after the injection. In 11 patients another reading of the pulmonary capillary venous pressure was taken in the 35th minute after injection. After serpasil the pulmonary arterial pressure changes during the period of estimation of the second oxygen consumption (i.e. 30th minute) were recorded and compared with the readings at the end of the rest period.

When evaluating the results, only changes above 10 per cent of the initial value were considered. Changes of pulmonary capillary venous pressure greater than $1.5 \mathrm{~mm}$. $\mathrm{Hg}$ and of mean brachial artery pressure above $5 \mathrm{~mm}$. $\mathrm{Hg}$ were evaluated.

TABLE II

Hemodynamic Data of 17 Patients with Chronic Pulmonary Diseases

\begin{tabular}{|c|c|c|c|c|c|c|c|c|c|c|c|c|c|c|c|c|c|c|}
\hline & \multicolumn{2}{|c|}{ PPA } & \multicolumn{2}{|c|}{$\begin{array}{c}\text { PCV } \\
\text { pressure }\end{array}$} & \multicolumn{2}{|c|}{ PBA } & \multicolumn{2}{|c|}{ TPR } & \multicolumn{2}{|c|}{ PVR } & \multicolumn{2}{|c|}{ SR } & \multicolumn{2}{|c|}{ CO } & \multicolumn{2}{|c|}{ Pulse } & \multicolumn{2}{|c|}{$\begin{array}{c}\mathrm{O}_{2} \\
\text { Saturation }\end{array}$} \\
\hline & B & $A$ & B & $\mathbf{A}$ & B & $\mathbf{A}$ & B & $\mathbf{A}$ & B & $\mathbf{A}$ & B & A & B & $\mathbf{A}$ & B & $\mathbf{A}$ & B & A \\
\hline $\begin{array}{r}1 \\
2 \\
3 \\
4 \\
5 \\
6 \\
7 \\
8 \\
9 \\
9 \\
10 \\
11 \\
12 \\
13 \\
14 \\
15 \\
16\end{array}$ & $\begin{array}{l}68.1 \\
39.7 \\
20.8 \\
22.6 \\
25.8 \\
16.4 \\
24.4 \\
17.2 \\
25.4 \\
20.2 \\
32.4 \\
21.4 \\
21.7 \\
20.7 \\
22.5 \\
21.1 \\
41.1\end{array}$ & $\begin{array}{l}64 \cdot 8 \\
30.2 \\
116.2 \\
23.8 \\
19 \cdot 3 \\
13.7 \\
20.9 \\
117.1 \\
22.0 \\
116.3 \\
230.6 \\
20.0 \\
19 \cdot 1 \\
116.6 \\
117.9 \\
36.9\end{array}$ & $\begin{array}{r}11.0 \\
5.1 \\
8.8 \\
9.1 \\
6.0 \\
2.7 \\
3.7 \\
6.1 \\
12.6 \\
4.8 \\
8.5 \\
11.4 \\
5.3 \\
2.5 \\
4.6 \\
5.9 \\
1.4\end{array}$ & $\begin{array}{c}\bar{Z} \\
\overline{9 \cdot 4} \\
7.6 \\
5.1 \\
2 \cdot 0 \\
\overline{6 \cdot 1} \\
12 \cdot 4 \\
4.6 \\
\overline{7} \\
\overline{6 \cdot 5} \\
4.5 \\
14 \cdot 9 \\
2.5\end{array}$ & $\begin{array}{r}85.0 \\
93.3 \\
105.8 \\
86.6 \\
76.6 \\
102.2 \\
100.0 \\
96.6 \\
78.8 \\
101.6 \\
133.3 \\
97.5 \\
88.3 \\
96.6 \\
96.6 \\
94.9 \\
100.0\end{array}$ & $\begin{array}{r}79.1 \\
105.0 \\
103.3 \\
83.3 \\
79.3 \\
103.3 \\
100.0 \\
96.6 \\
80.0 \\
100.0 \\
150.0 \\
93.3 \\
110.0 \\
96.6 \\
90.0 \\
83.3 \\
100.0\end{array}$ & $\begin{array}{r}1170 \\
395 \\
477 \\
649 \\
3999 \\
292 \\
638 \\
292 \\
292 \\
360 \\
387 \\
2955 \\
340 \\
3431 \\
4432 \\
986\end{array}$ & $\begin{array}{l}860 \\
328 \\
338 \\
517 \\
260 \\
215 \\
515 \\
255 \\
286 \\
244 \\
272 \\
203 \\
316 \\
280 \\
336 \\
362 \\
767\end{array}$ & $\begin{array}{l}982 \\
344 \\
276 \\
443 \\
306 \\
241 \\
537 \\
188 \\
147 \\
275 \\
286 \\
138 \\
230 \\
390 \\
302 \\
311 \\
952\end{array}$ & $\begin{array}{c}\bar{T} \\
142 \\
352 \\
191 \\
183 \\
164 \\
125 \\
175 \\
\overline{209} \\
204 \\
204 \\
714 \\
714\end{array}$ & $\begin{array}{l}1462 \\
924 \\
2441 \\
1967 \\
1192 \\
1796 \\
2652 \\
1650 \\
1903 \\
1811 \\
1587 \\
1329 \\
1562 \\
2067 \\
1625 \\
1952 \\
2400\end{array}$ & $\begin{array}{l}1050 \\
1142 \\
2150 \\
1808 \\
1080 \\
1621 \\
2460 \\
1450 \\
1043 \\
1500 \\
1726 \\
949 \\
1825 \\
1140 \\
1666 \\
11680 \\
2133\end{array}$ & $\begin{array}{l}4.65 \\
8.07 \\
3.48 \\
3.54 \\
5.17 \\
4.54 \\
3.02 \\
4.70 \\
6.979 \\
46.50 \\
5.85 \\
4.53 \\
3.73 \\
4.75 \\
3.90 \\
3.33\end{array}$ & $\begin{array}{l}7.35 \\
3.8 \\
3.6 \\
5.92 \\
5.08 \\
3.2 \\
5.3 . \\
6.1 \\
5.3 \\
6.92 \\
7.8 \\
4.8 \\
4.7 \\
4.3 \\
3.9 \\
3.9\end{array}$ & $\begin{array}{r}93 \\
111 \\
84 \\
96 \\
108 \\
103 \\
78 \\
78 \\
94 \\
988 \\
108 \\
84 \\
102 \\
72 \\
86 \\
78 \\
96\end{array}$ & $\begin{array}{r}93 \\
120 \\
78 \\
96 \\
114 \\
102 \\
78 \\
72 \\
88 \\
102 \\
108 \\
90 \\
108 \\
72 \\
78 \\
66\end{array}$ & $\begin{array}{l}64.0 \\
78.0 \\
92.0 \\
90.0 \\
84.5 \\
980.3 \\
93.0 \\
98.0 \\
887.0 \\
90.7 \\
88.3 \\
88.5 \\
89.5 \\
90.1 \\
83.2 \\
69.2\end{array}$ & $\begin{array}{l}55.8 \\
77.0 \\
89.7 \\
89.0 \\
84.5 \\
84.0 \\
95.0 \\
87.0 \\
86.0 \\
90.5 \\
87.0 \\
87.2 \\
85.0 \\
71.0 \\
70.7\end{array}$ \\
\hline
\end{tabular}

$\mathbf{B}=$ before administration of serpasil $\mathbf{A}=$ after administration of serpasil PPA = mean pulmonary artery pressure PCV pressure = pulmonary capillary venous pressure in $\mathbf{m m} . \mathbf{H g}$ PBA = mean brachial artery pressure
TPR = total pulmonary resistance in dyn. $/ \mathrm{sec} . / \mathrm{cm} .^{-5}$

PVR = pulmonary vascular resistance in dyn. $/ \mathrm{sec} . / \mathrm{cm} .^{-5}$ $\mathbf{S R}=$ systemic resistance in dyn. $/ \mathrm{sec} . / \mathrm{cm} .^{-5}$

$\begin{aligned} \mathrm{CO} & =\text { cardiac output in litres/min. } \\ \mathrm{O}_{2} \text { sat } & =\text { arterial oxygen saturation. }\end{aligned}$ 
Table II summarizes hæmodynamic data in individual patients, and in Table III changes of the central hæmodynamics after reserpine in patients with chronic pulmonary disease are compared with data obtained by Halmagyi in patients with mitral stenosis.

It is seen in Table II that in most patients (in 13 out of 17) the mean pulmonary arterial pressure was decreased after reserpine, but in four it remained unchanged. In no patient was there a rise of a mean pulmonary artery pressure. The cardiac output remained unchanged in eight patients, dropped in one and rose in eight. The mean brachial artery pressure remained unchanged in 14 patients, rose in two and decreased in one.

Thus in most patients the pressure in the lesser circulation decreased after reserpine. The pulmonary capillary venous pressure and the pressure in the systemic circulation did not change substantially and the cardiac output either remained unchanged or increased. The values of the total pulmonary and pulmonary vascular resistance decreased, while at the same time the resistance in the systemic circulation might rise or decrease or remain unchanged.

The arterial oxygen saturation decreased by more than 2 per cent in a minority of patients (6 out of 17) and in 11 it did not change substantially. The fall in pressure in the pulmonary artery did not appear before the 20th minute and in most cases it persisted to the end of the observation period. It reached its maximum during the 30th minute after injection.

Our results correspond on the whole to those obtained by Halmagyi (1959) in patients with mitral stenosis. Minor differences were found only in the behaviour of the pulmonary capillary venous pressure and the cardiac output. As is apparent from Table III, the pulmonary capillary venous

TABLE III

Changes in Hemodynamics AFter Reserpine

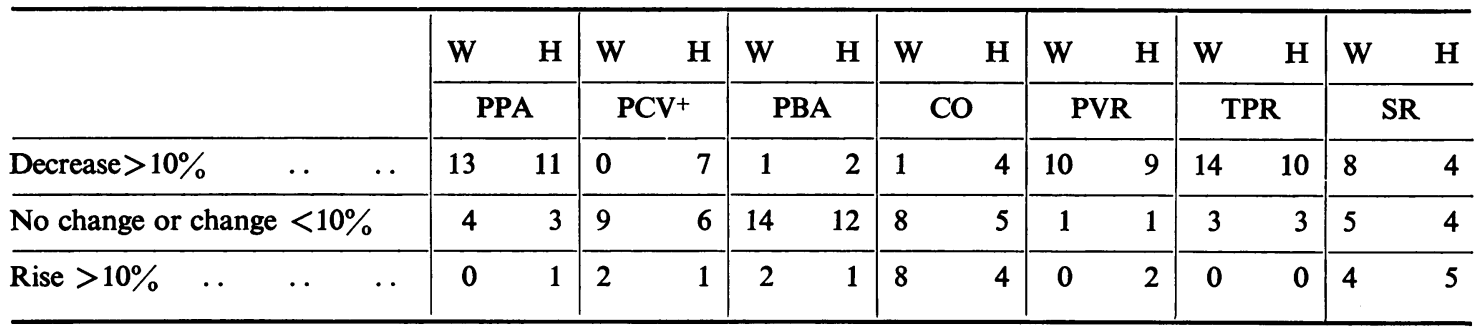

$\mathbf{W}=$ our data

$\mathbf{H}=$ Halmagyi

PPA $=$ mean pulmonary artery pressure

$\mathrm{PCV}^{+}=$pulmonary capillary venous pressure: only changes greater than $1.5 \mathrm{~mm}$. $\mathrm{Hg}$ were evaluated
PBA $=$ mean brachial artery pressure $\mathrm{CO}=$ cardiac output

$\mathbf{P V R}=$ pulmonary vascular resistance

$\mathrm{TPR}=$ total pulmonary resistance

$\mathbf{S R}=$ systemic resistance

pressure decreased very frequently in patients with mitral stenosis, whereas in our group of patients there was no single instance of fall of more than $1.5 \mathrm{~mm}$. $\mathrm{Hg}$. This difference may be due to a lower heart rate in mitral stenosis patients after reserpine. On the other hand we recorded a rise of cardiac output more frequently than it was found by Halmagyi in patients with mitral stenosis.

Among patients with pulmonary diseases, the mean pulmonary arterial pressure decreased after reserpine, whereas the pressure in the systemic circulation and the pulmonary capillary venous pressure did not change substantially (Table IV). The calculated values of the pulmonary vascular resistance and the total pulmonary resistance decreased. Changes in the pulse rate were not significant: the cardiac output thus rose mainly as a result of an increase of the stroke volume.

The pressure in the pulmonary artery decreased independently of the changes in the pulmonary blood flow. In seven patients of our group the pressure in the pulmonary artery decreased, though the pulmonary blood flow and the pulmonary capillary venous pressure were unchanged. 
TABLE IV

Changes in Central Hamodynamics after Reserpine (Average Values)

\begin{tabular}{c|c|c|c|c|c|c|c|c|c}
\hline & PPA & PCV & PBA & TPR & PVR & SR & CO & $\begin{array}{c}\text { Heart } \\
\text { rate }\end{array}$ & $\begin{array}{c}\mathrm{O}_{2} \\
\text { saturation }\end{array}$ \\
\hline B & 27.3 & 5.9 & 96.1 & 483 & 338 & 1725 & 4.79 & 92.3 & 85.4 \\
\hline A & 23.3 & 6.9 & 97.2 & 374 & 230 & 1584 & 5.19 & 91.5 & 83.6 \\
\hline $\begin{array}{c}\mathrm{t}=6.42 \\
\mathrm{p} 0.001\end{array}$ & $\begin{array}{c}\mathrm{t}=1.10 \\
\text { not sign. }\end{array}$ & $\begin{array}{c}\mathrm{t}=0.56 \\
\text { not sign. }\end{array}$ & $\begin{array}{c}\mathrm{t}=5.65 \\
\mathrm{p} 0.001\end{array}$ & $\begin{array}{c}\mathrm{t}=4.65 \\
\mathrm{p} 0.01\end{array}$ & $\begin{array}{c}\mathrm{t}=2.62 \\
\mathrm{p} \mathrm{0.02}\end{array}$ & $\begin{array}{c}\mathrm{t}=2.34 \\
\mathrm{p} 0.05\end{array}$ & $\begin{array}{c}\mathrm{t}=0.93 \\
\text { not sign. }\end{array}$ & $\begin{array}{c}\mathrm{t}=2.87 \\
\mathrm{p} 0.02\end{array}$ \\
\hline
\end{tabular}

$\mathrm{B}=$ before reserpine

$A=$ after reserpine

PPA = mean pulmonary artery pressure in $\mathrm{mm} . \mathbf{H g}$

$\mathrm{PCV}=$ pulmonary capillary venous pressure

PBA $=$ mean brachial artery pressure
$\mathrm{TPR}=$ total pulmonary resistance in dyn. $/ \mathrm{sec} . / \mathrm{cm} .^{-5}$

PVR = pulmonary vascular resistance in dyn. $/ \mathrm{sec} . / \mathrm{cm} .^{-5}$

$\mathrm{SR}=$ systemic resistance in dyn. $/ \mathrm{sec} . / \mathrm{cm} .^{-5}$

$\mathrm{CO}=$ cardiac output in litre/min.

$\mathrm{SaO}_{2}=$ arterial oxygen saturation

\section{DisCUSSION}

The pressure in the pulmonary artery may drop as a result of (i) a decreased pulmonary blood flow; (ii) decreased pressure in the left atrium, or (iii) a decreased resistance in the lesser circulation. We did not encounter a decrease of the pressure in the left atrium as far as any conclusions could be drawn from changes in the pulmonary capillary venous pressure in any patient and only in one did the pulmonary blood flow decrease by more than 10 per cent of the initial value. The mechanism of the decrease of resistance in the pulmonary circulation, however, can be manifold. The resistance may drop, for instance, as a result of an increased pulmonary blood flow, since the increased blood flow has the tendency to dilate simultaneously the pulmonary arteries (mainly in healthy subjects). But despite this "dilating effect" of the increased blood flow the pressure in the pulmonary artery rises or at least does not change. In our patients we did not observe, however, that a rise of the blood flow through the lungs was associated with a decrease of the mean pulmonary arterial pressure.

It is possible that, in those patients in whom the decreased pressure in the pulmonary artery was associated with a decreased resistance in the systemic circulation, a shift of blood from the lesser to the greater circulation occurred, so that decreased pressure in the lesser circulation was only a secondary phenomenon, due to a decrease in the volume of blood in the lungs. In seven patients the pressure in the lesser circulation decreased after reserpine, though the pulmonary blood flow and the pulmonary capillary venous pressure remained unchanged. It is probable that in these patients a dilatation of the pulmonary vessels occurred after reserpine.

Pressure changes in the lesser circulation were similar to those recorded in our previous work on priscol (Widimský et al., 1960), but the duration of the hypotensive effect of reserpine was longer. In contrast with the action of priscol, the extent of changes after reserpine did not depend on the initial values. The onset of the effect of reserpine was identical with that recorded by Halmagyi. The decrease in the oxygen saturation of arterial blood was encountered only in six patients. It was probably due to the change in the ratio of perfusion and ventilation-i.e. an increased blood supply to hypoventilated portions of the pulmonary parenchyma (Söderholm and Werkö, 1959).

Our results therefore indicate that reserpine injected by a catheter into the pulmonary artery has in most patients with chronic pulmonary disease a hypotensive effect on the pressure in the pulmonary artery. Nevertheless, this effect was not recorded in all patients and in some it was not very great. As regards the therapeutic aspect, reserpine appears to be more suitable than priscol for the treatment of pulmonary hypertension in chronic pulmonary disease. It remains doubtful whether smaller doses administered orally will exert a similar hypotensive action. 


\section{SUMMARY}

The effect of the injection of 1-2 mg. of reserpine (serpasil, Ciba) into the pulmonary artery during catheterization in 17 patients with chronic pulmonary disease has been investigated. In 13 of them a decrease of the pressure in the pulmonary artery was recorded, whereas the pulmonary capillary venous pressure and the pressure in the systemic circulation did not change. The cardiac output either did not change or increased; the resistance in the systemic circulation either remained unchanged or lessened. The total pulmonary and pulmonary vascular resistance decreased after the administration of reserpine.

\section{REFERENCES}

Angelino, P. F., and Levi, V. (1956). Minerva Cardioangiologica, 4, 174.

Halmagyi, D., Felkai, B., Czipott, Z., Kovács, G. (1957). Brit. Heart J., 19, 375.

Söderholm, B., and Werkö, L., (1959). Brit. Heart J., 21, 1.

Widimský, J., Kasalický, J., Valach, A., Dejdar, R., Vysloužil, S., and Lukeš, M. (1960). Brit. Heart J., $22,571$. 